\title{
OPTIMAL BUDGET ASSIGNMENT FOR SERVICE QUALITY IMPROVEMENT IN DISTRIBUTION NETWORKS
}

\author{
J M LÓPEZ-LEZAMA ${ }^{1}$, F VILLADA DUQUE ${ }^{2} \&$ EDWINRIVAS TRUJILLO ${ }^{3}$ \\ ${ }^{1}$ Departamento de Ingeniería Eléctrica, Universidad de Antioquia, Calle 67 No 53-108, Medellín, Colombia. \\ ${ }^{2}$ Departamento de Ingeniería Eléctrica, Universidad de Antioquia, Calle 67 No 53-108, Medellín, Colombia. E-mail \\ ${ }^{3}$ Grupo de Investigación Interferencia Electromagnética (GCEM), Ingeniería Eléctrica, Facultad de Ingeniería, Universidad \\ Distrital Francisco José de Caldas, Cra 7 No 40B-53, Bogotá, Colombia
}

\begin{abstract}
This paper presents a multi-objective approach for optimal budget assignment in distribution systems. Two conflicting objective functions are taken into account: minimizing maintenance costs and maximizing service quality. The last objective is measured through the System Average Interruption Frequency Index (SAIFI). A Non-Dominated Sorting Genetic Algorithm II (NSGAII) is implemented to solve the proposed model. Several tests are carried out on two real-life distribution system evidencing the applicability and effectiveness of the proposed methodology. The optimal Pareto front obtained though the NSGAII shows the different trade-offs between the two objectives and provides distribution system planners and operators an estimate on how much to invest in maintenance in order to achieve a desired SAIFI level.

KEYWORDS: Optimal Budget, Distribution Networks \& Service Quality
\end{abstract}

Received: Jun 08, 2020; Accepted: Jun 28, 2020; Published: Oct 07, 2020; PaperId.: IJMPERDJUN20201482

\section{INTRODUCTION}

In the business of electrical energy distribution, regulatory and control entities define quality of service indicators that must be addressed by distribution companies. These indicators are related to the duration and frequency of interruptions to users. Failure to meet certain levels in these indicators may lead distribution companies to pay fines or compensation to affected users [1]. Given the complexity of distribution systems and the variability of reliability performance in these systems, it is necessary to apply optimization tools that facilitate planning decisions for distribution engineers. In the specialized literature, different methodologies have been proposed for scheduling the maintenance of distribution networks with the aim of impacting service quality. In [2] the authors present a method of preventive maintenance budget allocation in distribution networks. Based on a reliability based maintenance technique, the candidate failures to be managed are identified with the objective of reducing the occurrence rate. In addition, surveys of experts determine the impact on reliability. Then the optimal assignment of the maintenance budget by region for a distribution company is formulated. In [3] a methodology is presented to obtain the optimal Pareto front in a multi-objective maintenance problem that aims to minimize the total maintenance cost and its time. The methodology is based on evolutionary algorithms and an application in the maintenance of a military naval unit is presented.

The authors in [4] propose a genetic algorithm for network reconfiguration and maintenance scheduling in distribution systems. To reduce the search space, operators are adopted to generate feasible solutions in the 
algorithm coding. The objective function consists of the minimization of active losses and the maintenance cost. In [5] the authors propose an optimal schedule for the maintenance of distribution networks with the aim of minimizing the energy not served due to failures caused by vegetation. The solution of the proposed model is achieved through a specialized genetic algorithm. The problem is approached from a mono-objective perspective considering as a restriction the resources available to carry out maintenance activities. In [6] the authors propose tools for the optimal scheduling of maintenance activities that tend to optimize costs and, indirectly, to improve quality indicators.

In [7] a multi-agent system is used to monitor quality indicators in distribution systems. The authors develop software to record failures in distribution networks, which allows the real-time computation of several service quality indexes. In [8] the authors present an approach to improve the momentary average interruption frequency index in distribution networks. This quality of service indicator is monitored to mitigate its effects and find its possible causes through an automatically constructed information report which includes several data gathered from weather conditions as well as the type of fault and its location.

In the technical literature, the use of metaheuristics in distribution system studies is found recurrently. This paper presents an optimal budget assignment approach for service quality improvement in distribution systems. The contributions of this paper are twofold: 1) the quality index is proposed as one of the objectives of the problem and not as a constraint as commonly used in other works and 2) a trade-off between quality levels and maintenance cost is presented, which allows the system planner to kwon the amount of investments required for a desired quality level.

\section{MATHEMATICAL FORMULATION}

The proposed model involves two objective functions: i) the minimization of maintenance cost and ii) the maximization of the reduction in the failure rate. The reduction of the failure rate is evaluated through the SAIFI indicator (Average Frequency of System Interruption) that indicates the average number of times that a client of the system suffers an interruption during the period of time analyzed, as indicated in the equation (1). In this case, $\mathrm{N}$ is the set of buses, $\mathrm{x}_{\mathrm{i}}$ is the binary variable that defines whether the network section is intervened with maintenance actions, $\mathrm{c}_{\mathrm{i}}$ and $\mathrm{ct}$ are parameters that indicate the number of customers affected by a service interruption and the total number of customers in the electrical system, respectively. Finally, $\lambda_{\mathrm{i}}$ is the parameter that indicates the number of interruptions of the element per year.

$$
\operatorname{Max} \Delta \text { SAIFI }=\frac{1}{c t} \sum_{i \in \mathrm{N}} \lambda_{\mathrm{i}} * \mathrm{c}_{\mathrm{i}} \prod_{\mathrm{K}=\mathrm{i}+1}^{\mathrm{n}} \mathrm{x}_{\mathrm{i}}
$$

The maintenance cost is given by equation (2) where $x_{i}$ is the binary variable that defines whether the network section is intervened with maintenance actions, while $d_{i}$ and $l_{i}$ are parameters that indicate the cost of intervening one kilometer of network and the kilometers of network downstream of the sectioning elements, respectively.

$$
\text { Mincosto }=\sum_{i \in \text { Nodos }} d_{i} * l_{i} \prod_{K=i+1}^{n} x_{i}
$$

Initially, an unrestricted problem is considered where it is intended to know the Pareto front of the solution, in order to identify the potential for improvement of the SAIFI and its associated cost. Once a cost goal (labeled as $k$ ), or 
improvement of SAIFI (labeled as $e$ ), is defined, the constratins given by (3) and (4) can be included.

$$
\begin{gathered}
\frac{1}{\mathrm{ct}} \sum_{\mathrm{i} \in \mathrm{N}} \lambda_{\mathrm{i}} * \mathrm{c}_{\mathrm{i}} \prod_{\mathrm{K}=\mathrm{i}+1}^{\mathrm{n}} \mathrm{x}_{\mathrm{i}} \leq \mathrm{e} \\
\sum_{i \in N} d_{i} * l_{i} \prod_{K=i+1}^{n} x_{i} \leq k
\end{gathered}
$$

The decision variable of the problem is given by the binary variable $x_{i}$. If this variable takes the value 1 , it indicates that the corresponding section is a candidate to be intervened or maintained, contributing to the reduction of the failure rate; if the value is 0 it indicates that the section is not intervened.

\section{SOLUTION APPROACH}

When dealing with multi-objective problems, the concept of dominance must be taken into account. Given a solution $\mathrm{x}_{1}$, this one is said to dominate another solution $x_{2}$ when: a) solution $x_{1}$ is not worse than $x_{2}$ on any of the objectives and b) solution $x_{1}$ is strictly better than $x_{2}$ on at least one objective. If either of these two conditions is not met, then $x_{1}$ does not dominate $\mathrm{x}_{2}$. The concept of dominance is used to find a set of non-dominated solutions, called the Pareto front. The NSGAII belongs to the family of evolutionary algorithms that allows finding this set of solutions. Due to the fact that none of the solutions in the non-dominated set is absolutely better than the others; then, any one of these can be considered an acceptable solution.

The NSGAII was developed in [9]. In this methodology, a new population labeled as Qt and containing $\mathrm{N}$ individuals is created from a population of parents, labeled as $\mathrm{Pt}$ (also with $\mathrm{N}$ individuals). The two populations make up the Rt set of size 2N. Subsequently, using a non-dominated ordering, the Rt population is classified on different Pareto fronts. The new population is generated from the non-dominated front configurations. The population starts to be built using the best non-dominated front (labeled as F1), continuing with the solutions of the second front (F2) and so on. Since $\mathrm{Rt}$ is $2 \mathrm{~N}$ in size but only $\mathrm{N}$ individuals are needed for the descendant population, $\mathrm{N}$ configurations must be discarded. Individuals belonging to the minor front are preferred, if both belong to the same front, the individual with fewer solutions around is preferred. The main idea consists on promoting configurations that ensure diversity within the same Pareto front. When the whole population converges to the optimal Pareto front, the procedure guarantees that the solutions are distanced from one another. Figure 1 illustrates the NSGAII individual selection process. A detailed description of the NSGAII can be found in [9] and [10].

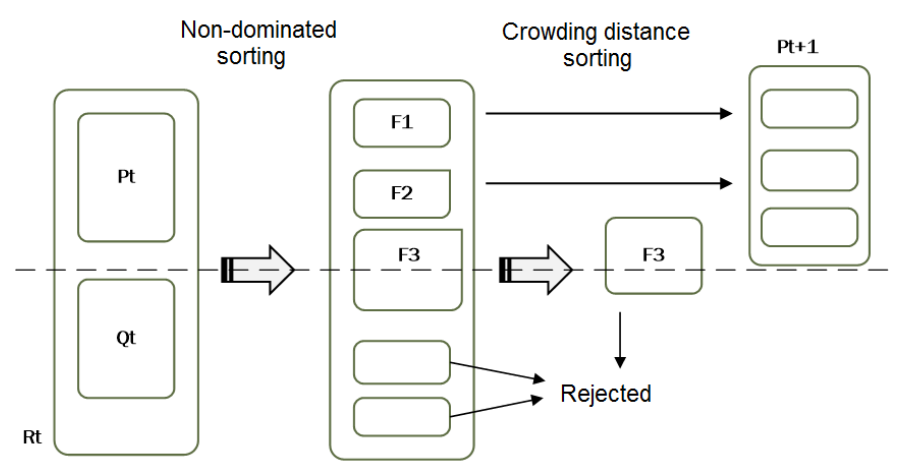

Figure 1: Illustration of the NSGA-II selection process. 
The implemented algorithm starts from a randomly generated initial population Po. Once the initial population is obtained, the descendant population Qo is generated (it is denoted as Qt for future generations). Then, the objective function is calculated and the dominance population classification is made. Subsequently, the selection, crossing and mutation operators are applied. To maintain the diversity of the population, elitism is implemented. That is, in all selection operations, the population density in the vicinity of an individual is used as a secondary measure of adaptation. Every time two individuals are compared, a comparator is used to know which one is best adapted. The individual who belongs to the least front is preferred, and if both belong to the same front, the solution with fewer solutions around is preferred. The process stops when a predefined number of generations is reached.

\section{TEST AND RESULTS}

The proposed approach was tested in two distribution networks of 100 and 200 nodes located in the department of Antioquia in Colombia. These circuits supply energy to rural clients in areas with similar geographical characteristics and operational context. Table 1 shows the main data of the distribution systems.

Table 1: Characteristics of the test systems

\begin{tabular}{|c|c|c|}
\hline Characteristic & Test System 1 & Test System 2 \\
\hline Number of buses & 100 & 200 \\
\hline Length [km] & 1268 & 2220 \\
\hline Number of Clients & 13245 & 26839 \\
\hline Maintenance cost [Million USD] & 0,789 & 1,098 \\
\hline Max SAIFI improvement & 5,886 & 5,681 \\
\hline
\end{tabular}

Initially, several tests are carried out to calibrate the parameters of the algorithm. Figure 2 shows the performance of the NSGA-II regarding the standard deviation with respect to the best solution found and the ratio populationgenerations for Test System 1. 50 runs of the algorithm were executed for each trial. It was found that for populations over 75 individuals the computation time increases but the standard deviations remain the same, despite of the fact of increasing the number of generations. On the other hand, for populations of 50 individuals the standard deviation presented variations with the number of generations. In this case, the selected parameters are 75 individuals and 30 iterations since they allow an adequate trade-off between reproducibly of results and computational time.

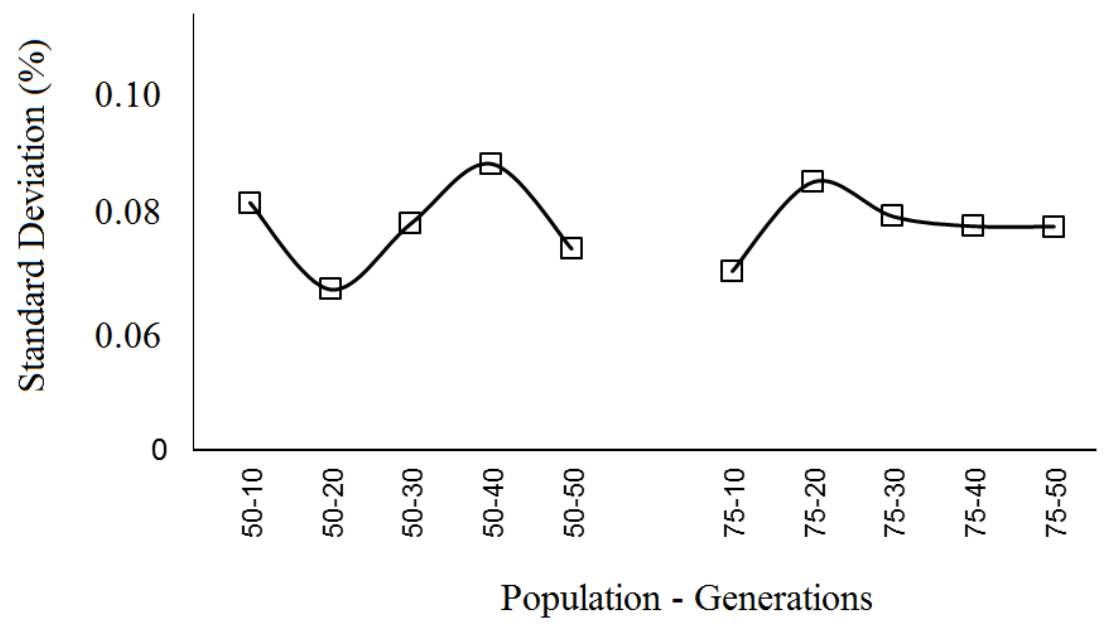

Figure 2: Performance of the algorithm for Test System 1. 
The aforementioned analysis was also performed with Test System 2. Figure 3 depicts the performance of the NSGA-II for different sets of population and generations. In this case, the parameters selected are 75 individuals and 20 iterations since they allow low computational time and also present a low standard deviation.

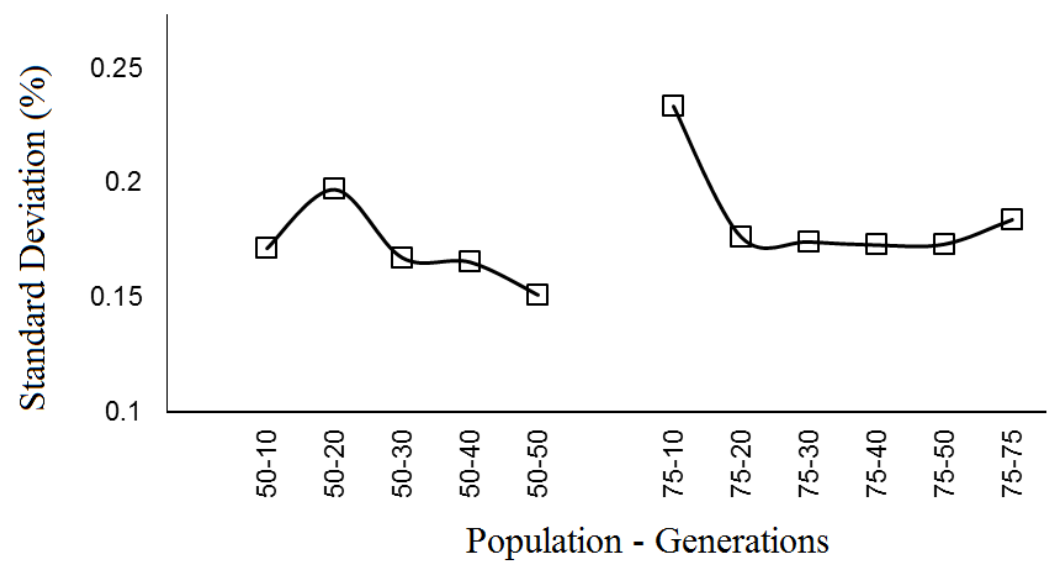

Figure 3: Performance of the algorithm for Test System 2.

Figure 4 and Figure 5 present the optimal Pareto fronts for Test System 1 and Test System 2, respectively. The optimal Pareto front is a set of non-dominated solutions that represent a trade-off between the conflicting objectives. Note that for Test System 1 it is possible to achieve an improvement of the SAIFI indicator (reduction of fault rates) of 5 units; however it requires an investment of nearly 0.7 Million USD, compared to an investment of only 0.1 Million USD that would only improve this indicator in 1 unit. As for Test System 2 a similar range of improvement in SAIFI is attainable; however at greater costs. One of the advantages of this methodology is the fact that the system planner is able to choose from a set of solutions according to a given budget.

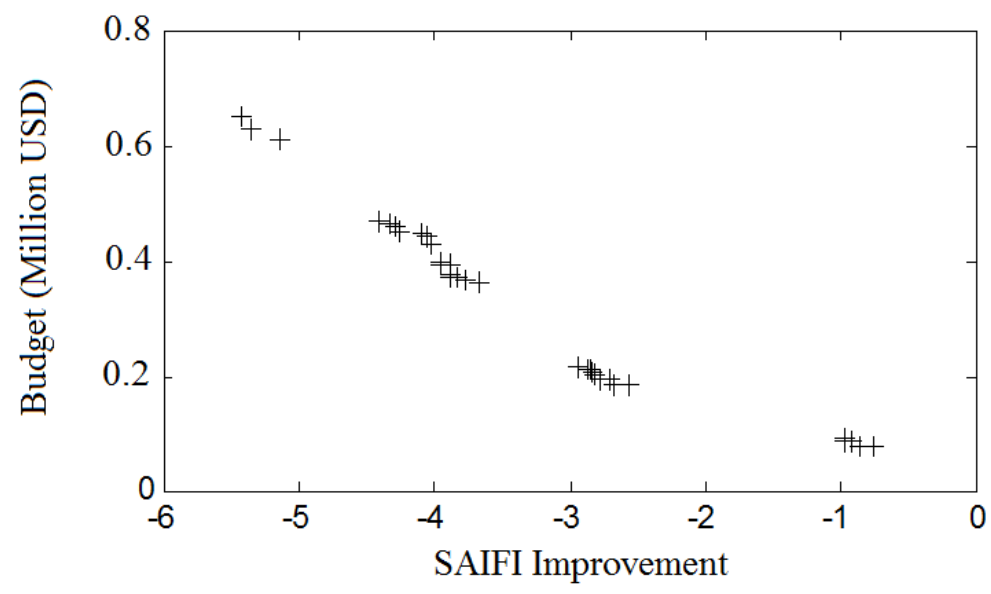

Figure 4: Optimal Pareto front for Test System 1. 


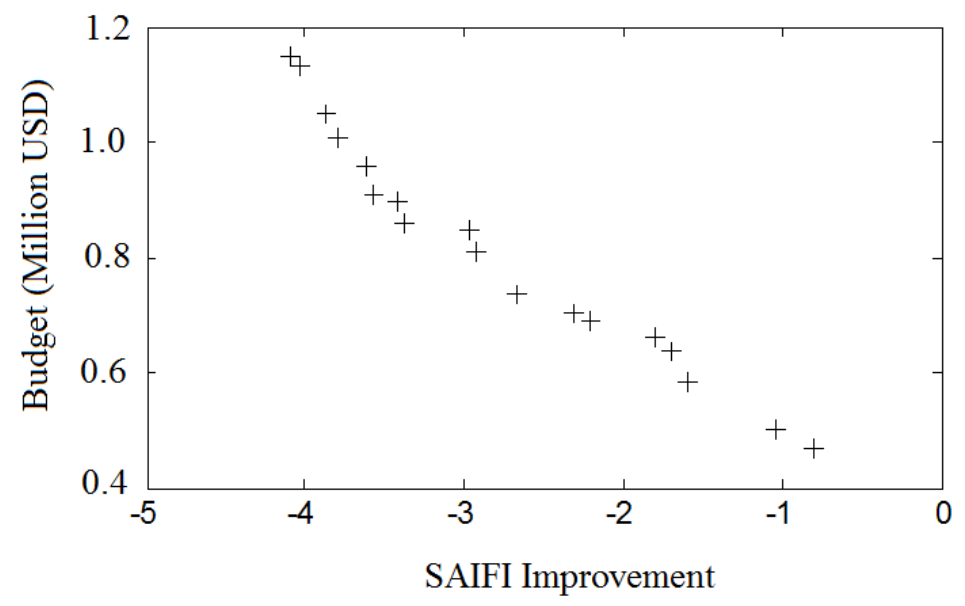

Figure 5: Optimal Pareto front for Test System 2.

\section{CONCLUSIONS}

This paper presented a multi-objective approach for optimal budget assignment in distribution systems. Two conflicting objectives which consist on minimizing investment and improving quality service are taken into account. The NSGA-II algorithm was implemented for finding the best set of trade-offs (optimal Pareto front) of these two objectives. Several tests were performed with two real distribution systems showing the applicability of the proposed approach. As expected, it was found that greater budget assignment results in higher quality indexes and vice versa. One of the advantages of the proposed methodology it is ease applicable to real-size distribution systems such as the ones presented in this paper. In addition, the distribution network operator is given a set of solutions that represent a compromise between the improvement of the quality indicator and the cost associated with it. With this information and a given budget it is possible to kwon in advance the impact on service quality.

\section{ACKNOWLEDGMENT}

The authors would like to acknowledge the sustainability program of Universidad de Antioquia.

\section{REFERENCES}

1. C. A. García Montoya, J. M. López-Lezama, y T. Gómez San Román, “Estimación del gasto total (TOTEX) de empresas de distribución mediante modelos de red de referencia y fronteras de eficiencia”, jul. 2019, Consultado: jul. 06, 2020. [En línea]. Disponible en: https://repositorio.comillas.edu/xmlui/handle/11531/37774.

2. N. Teera-achariyakul, K. Chulakhum, D. Rerkpreedapong, y P. Raphisak, "Optimal Allocation of Maintenance Budgets for Reliability Target Setting”, en 2010 Asia-Pacific Power and Energy Engineering Conference, mar. 2010, pp. 1-4, doi: 10.1109/APPEEC.2010.5448913.

3. A. Certa, G. Galante, T. Lupo, y G. Passannanti, "Determination of Pareto frontier in multi-objective maintenance optimization”, Reliab. Eng. Syst. Saf., vol. 96, núm. 7, pp. 861-867, jul. 2011, doi: 10.1016/j.ress.2010.12.019.

4. Y. Liu, X. Meng, y W. Sheng, "Research and application of maintenance schedule optimization based on intelligent algorithm”, en 2011 International Conference on Advanced Power System Automation and Protection, oct. 2011, vol. 2, pp. 957-961, doi: 10.1109/APAP.2011.6180537. 
5. A. Arias, R. A. Hincapie, M. Granada, y R. A. Gallego, "Optimal scheduling of vegetation maintenance underneath overhead power distribution lines", en 2012 Sixth IEEE/PES Transmission and Distribution: Latin America Conference and Exposition (T D-LA), sep. 2012, pp. 1-6, doi: 10.1109/TDC-LA.2012.6319097.

6. R. Arya y S. C. Choube, "Differential evolution based technique for reliability design of meshed electrical distribution systems”, Int. J. Electr. Power Energy Syst., vol. 48, pp. 10-20, jun. 2013, doi: 10.1016/j.ijepes.2012.11.021.

7. J. Sanchez Dominguez, A. J. Cerqueira Junior, D. Sanchez Dominguez, D. Frias, y S. Marrero Iglesias, "Using a Multi-Agent System for Monitoring Indicators of Quality of Service in Power Distribution Networks”, IEEE Lat. Am. Trans., vol. 13, núm. 4, pp. 1048-1054, abr. 2015, doi: 10.1109/TLA.2015.7106356.

8. M. Couto, J. Pascoal, J. Dias Matos, y J. Antunes, "Approach to reduce momentary average interruption frequency indexthe quality of service indicator for momentary interruptions - the experience of the Portuguese DSO”, CIRED - Open Access Proc. J., vol. 2017, núm. 1, pp. 522-525, 2017, doi: 10.1049/oap-cired.2017.0465.

9. K. Deb, A. Pratap, S. Agarwal, y T. Meyarivan, "A fast and elitist multiobjective genetic algorithm: NSGA-II", IEEE Trans. Evol. Comput., vol. 6, núm. 2, pp. 182-197, abr. 2002, doi: 10.1109/4235.996017.

10. V. L. Vachhani, V. K. Dabhi, y H. B. Prajapati, "Improving NSGA-II for solving multi objective function optimization problems", en 2016 International Conference on Computer Communication and Informatics (ICCCI), ene. 2016, pp. 1-6, doi: 10.1109/ICCCI.2016.7479921. 

